\title{
In Silico Design \& Development of Some Selected Flavonols Against Beta-Glucuronidase Inhibitory Activity
}

\author{
Sovan Pattanaik ${ }^{1}{ }^{*}$, Sudam Chandra $\mathrm{Si}^{1}$, Sudhanshu Sekhar Rout ${ }^{1}$, Anindya Bose ${ }^{1}$ and \\ Siva Shankar Nayak ${ }^{2}$
}

'School of Pharmaceutical Sciences, Siksha 'O'Anusandhan University, Bhubaneswar, Odisha-751003, India

${ }^{2}$ Siddhi Vinayaka Institute of Technology \& Sciences, Bilaspur, Chhattisgarh-495001, India

\begin{abstract}
Drug discovery process develops faster due to more advances in computational techniques. The protein ligand interaction well predicted due to the in-silico approach study. The present investigation focused towards the development of lead structure for treatment of hepatic disorders. An increase in serum acid hydrolase, including $\beta$ glucuronidase has been reported in numbers of pathological conditions such as arthritis, renal diseases and epilepsies. Enhancement of this enzyme $\beta$-glucuronidase in blood has been found to correlate significantly with liver damage. $\beta$ glucuronidase inhibitor is a novel approach which is different from the available hepatoprotective drug therapies.

Method: The current study is based on in-silico ligand screening and in-vitro estimation of the three flavonols [Naringenin, Quercetin and 2-(3, 4-Dihydroxy Phenyl)-7-Hydroxy-3-(2-Hydroxy Ethoxy) 4-H-Chromen-4one] compounds with enzyme $\beta$-glucuronidase. Molecular docking software Py Rex and Py Mol was used to dock the selected ligand in the binding site of the crystal structure of protein.

Results: Docking results are based on the least binding energy of the selected flavonols compounds. Further attempt has been made towards in-vitro estimation of this enzyme with those selected compounds. The binding affinity with existence of hydrogen bonds leads to find out the mechanism which was well correlated with the findings of in-vitro inhibitory activity.

Conclusion: The result outcome of the binding orientation of 2-(3, 4-Dihydroxy Phenyl)-7-Hydroxy-3-(2-Hydroxy Ethoxy) 4- $\mathrm{H}-$ Chromen-4one linked with the active amino acid residue of the protein and the binding affinity leads to find out the mechanism for its potential in-vitro inhibitory activity.
\end{abstract}

Keywords: Protein ligand, $\beta$-glucuronidase, serum acid, Chromen, binding affinity.

\section{INTRODUCTION}

Advances in computational techniques have enabled virtual screening to have a positive impact on the drug discovery process. The majority of biological processes are well-known through protein ligand interactions [1]. The three dimensional structure of the protein-ligand composite could be serve as a considerable source understanding the way of proteins interact with another and perform biological functions. Virtual Screening based studies on molecular level have become an integral part of many modern structure-based discovery efforts [2]. An advantage of this technique is that based on the predicted binding affinity data. Therefore activities can be quantified in a biochemical assay thereby reducing the time and expenditure in identifying new leads [3].

Flavonols in particular to Quercetin and Naringenin are continuously discussed on an account of their diverse biological properties. These flavonols and its derivatives are present in fruits, vegetables and leaves and are reported to have effective with several

*Address correspondence to this author at the School of Pharmaceutical Sciences, Siksha 'O'Anusandhan University, At- Kalinga Nagar, Land markNear SUM Hospital, Bhubaneswar, Odisha, Pin-751003, India;

Tel: 09437180498, 06746510751; E-mail: sovan.sps@gmail.com bioactivities including the anti-viral, anti-bacterial, anticarcinogenic and anti-inflammatory effects, rheumatism, nephrotoxicity, arthritis, urinary disorders, analgesic and the free radical scavenging activity [4-5]. The antioxidant and hepatoprotective activities of class of flavonoids cited in the literature make these compounds attractive for scientific enquiry, for further backbone derivatization and screening as novel therapeutic agents [6-7].

Lysosomes play an important role in cell death and tissue damage. They release hydrolytic enzymes that cause auto-digestion of cellular contents. Lysosomal membrane plays a vital role in maintaining the integrity of the cell. $\beta$-Glucuronidase present in animals and has been shown to be a typical lysosomal enzyme catalyzes the hydrolysis of $\beta$-glucuronidase conjugates of exogenous and endogenous compounds produced in the body [8]. The increase level of $\beta$-glucuronidase enzyme in blood has been found in variety of pathological conditions [9]. Furthermore, enhanced activity of this enzyme $\beta$-glucuronidase in blood has been found to correlate significantly with liver damage [10-11]. This enzyme also increased in liver cancer [12]. These findings depict that design and development of specific inhibitors of $\beta$-glucuronidase has great pharmacological importance. 
In considering to the above facts an attempt has been made to predict the binding mode analysis of the atoms of the compounds [Naringenin, Quercetin and isolated fraction of F3 i.e. 2-(3, 4-Dihydroxy Phenyl)-7Hydroxy-3-(2-Hydroxy Ethoxy) 4-H-Chromen-4one] reported previously [13] and involved amino acid in the protein responsible for enhancement disease related activity [14].

\section{METHODS}

\section{Preparation of Protein}

The enzyme $\beta$-glucuronidase was obtained from the RCSB Protein Data Bank with PDB ID 1BHG [14-15]. All water molecules were removed and Polar Hydrogen atoms were added to the enzyme structure. The 3D cartoon structure of the protein $1 \mathrm{BHG}$ is shown in the Figure 1.

\section{Preparation of Ligands}

The analogues of three compounds were identified from Pubchem compound database. The search parameters were set at $95 \%$ similarity subjected to Lipinski rule of five resulting with these compounds [1617]. The ligands were generated and three dimensional optimizations were done and then saved in mol file. The small-molecule topology generator Dundee PRODRG2 server is used for ligand optimization, a tool for high-throughput crystallography of protein-ligand complexes which takes input from existing coordinates or various two-dimensional formats and automatically generates coordinates and molecular topologies suitable for X-ray refinement of protein-ligand complexes. Molecular properties were calculated using Mol soft online server (http://molsoft.com/mprop/).

\section{Docking Software}

Molecular Graphics Laboratory (MGL tools-1.5.4) was used for docking preparation and Auto dock Vina was used for binding energy calculations. Auto dock performs the docking of ligand to a set of grids (pre calculated by auto grid) describing the target protein. The energy grid was performed based on Lamarckian genetic algorithm [18]. Virtual analysis of docking site was analyzed by PyRx and PyMol (version 1.4.0 and build 8.14.10.2230).

\section{Analysis and Visualization of Interactions in Docked Complexes}

The binding interactions in the docked complexes obtained by Auto dock vina were analyzed by PyMol software (Open Bable). The binding sites was set inside a restriction sphere of radius $78,50,84 \mathrm{~A}^{\circ}$ ( $\mathrm{X}, \mathrm{Y}$, $Z$ respectively) using vina wizard for docking analysis and were designed such that the entire ligand binding region was included within the GRID. Docking analysis of $1 \mathrm{BHG}$ with the QDs \& NDs was carried out using Auto dock Vina. Throughout the docking study the macromolecule was kept as rigid and ligand molecules were flexible [19]. The best pose of each compound

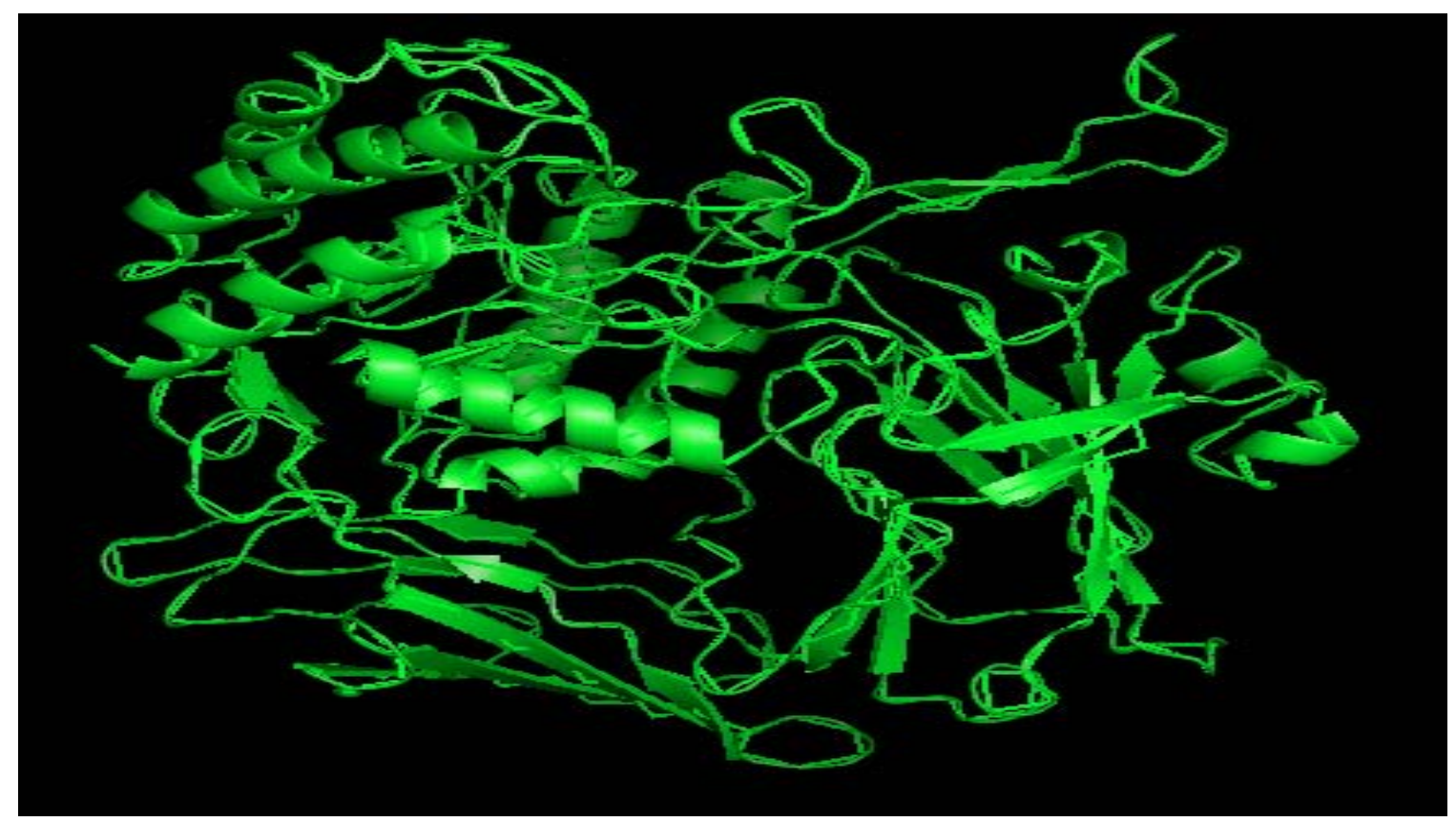

Figue 1: Structure of outer membrane protein of 1BHG (Human $\beta$-Glucuronidase at $2.6 A^{\circ}$ Resolution) obtained from RCSB Protein Data Bank online server and modify pymol analysis software. 
Table 1: Ligand Parameters of Compounds Used to Satisfy Lipinski's Rule of Five for Docking Analysis

\begin{tabular}{|c|c|c|c|c|c|c|c|}
\hline $\begin{array}{l}\text { Si } \\
\text { no }\end{array}$ & Ligand & ID & $\begin{array}{l}\text { Molecular } \\
\text { formula }\end{array}$ & $\begin{array}{c}\text { Molecular } \\
\text { weight }\end{array}$ & xLogP3 & HBD & HBA \\
\hline 1. & Naringenin & 439246 & $\mathrm{C}_{15} \mathrm{H}_{12} \mathrm{O}_{5}$ & 272.2527 & 2.4 & 3 & 5 \\
\hline 2. & Quercetin & 5280343 & $\mathrm{C}_{15} \mathrm{H}_{10} \mathrm{O}_{7}$ & 302.2357 & 1.5 & 5 & 7 \\
\hline 3. & $\begin{array}{c}\text { Quercetin derivative 2- (3, 4-Dihydroxy } \\
\text { Phenyl)-7-Hydroxy-3-(2-Hydroxy Ethoxy) } \\
\text { 4-H-Chromen-4one }\end{array}$ & 9818879 & $\mathrm{C}_{17} \mathrm{H}_{14} \mathrm{O}_{7}$ & 330.2888 & 1.6 & 4 & 7 \\
\hline
\end{tabular}

N.B. HBD: Hydrogen bond donor, HBA: Hydrogen bond acceptor.

Table 2: Binding Affinity (Kcal/mol) of $1 \mathrm{BHG}$ with Selected Ligands

\begin{tabular}{|c|c|c|c|c|}
\hline SI No. & ID & No of hydrogen bonds & Binding affinity (Kcal/mol) & Amino Acid Residues Involved \\
\hline \hline 1 & 439246 & 0 & -7.6 & NA \\
\hline 2 & 5280343 & 1 & -7.8 & ASN81 \\
\hline 3 & 9818879 & 8 & -8.3 & $\begin{array}{c}\text { GLU451, GLU520,TYR508,ARG600, } \\
\text { PHE206, ASN450 }\end{array}$ \\
\hline
\end{tabular}

NA: Not active.

was selected for the subsequent ligand protein interaction energy analysis.

\section{In- Vitro Analysis for Estimation of Inhibitory Potency of $\beta$-Glucuronidase Activity}

In this assay three compounds Quercetin, Naringenin and 2-(3, 4-Dihydroxy Phenyl)-7-Hydroxy-3(2-Hydroxy Ethoxy) 4-H-Chromen-4one was selected to determine the inhibition potency of $\beta$-glucuronidase enzyme, by measuring the absorbance at $405 \mathrm{~nm}$. The total reaction mixture $2.5 \mathrm{ml}$ consisted of $1.85 \mathrm{ml}$ of $0.4 \mathrm{mM}$ Phenolphthalein-mono- $\beta$-glucuronic acid, tested compounds $(50,100,150,200,250 \mu \mathrm{g} / \mathrm{ml})$ of $0.05 \mathrm{ml}$ in methanol and $0.1 \mathrm{ml}$ of enzyme solution (2.0 Fishman unit/ml Escherichia coli f3-glucuronidase) for $60 \mathrm{~min}$ at $37^{\circ} \mathrm{C}$ and $\mathrm{pH} 6.8$ [20]. Then the reaction was terminated by addition $0.5 \mathrm{ml}$ of $1 \mathrm{M}$ sodium hydroxide at $\mathrm{pH}$ 11. A development of pink color was measured at $400 \mathrm{~nm}$ by UV spectrophotometer. $0.5 \mathrm{ml}$ methanol only was taken control for this $\beta$-glucuronidase enzyme estimation.

(\%) of $\beta$-glucuronidase enzyme scavenging activity = $\left[\left(\right.\right.$ Abs control - Abs test $_{\text {t }} /\left(\right.$ Abs $\left.\left._{\text {control }}\right)\right] \times 100$

Where Abs control is the absorbance of $\beta$ glucuronidase enzyme+methanol; Abs sample is the absorbance of $\beta$-glucuronidase enzyme +test sample.

Absorbance of the control solution (after 30 minutes) $=0.16$

\section{RESULTS}

The ligand considered as a drug when that satisfy Lipinski's Rule of Five for docking analysis which was depicted in Table 1. Three numbers of flavonols showed their Hydrogen bond donor (HBD), Hydrogen bond acceptor (HBA) as well as Log $P$ value which were help to predict the character drug likingness of those selected ligand derivatives. Further, Table 2 showed the binding affinity of those selected ligand with the isolated protein (1BHG) involved in related disease. The characteristic of interaction involved numbers of hydrogen atoms, binding affinity expressed in $\mathrm{Kcal} / \mathrm{mol}$ and amino acid residue involved. The result of the study find the compound ID 9818879 i.e. (2-(3, 4Dihydroxy Phenyl)-7-Hydroxy-3-(2-Hydroxy Ethoxy) 4$\mathrm{H}$-Chromen-4one.) with $\mathrm{HBD}=4$ and $\mathrm{HBA}=7$ along with 8 numbers of hydrogen bonds, $-8.3 \mathrm{Kcal} / \mathrm{mol}$ of binding affinity. The predicted binding interaction was showed in Figure $3 c$ which reflected green dash lines towards various involved amino acids in the interactions as follows GLU451, GLU520, TYR508, ARG600, PHE206, ASN450. Whereas Figure 3b showed only one amino acids in the interactions ASN81 of protein 1BHG with Quercetin and Figure $3 \mathbf{a}$ showed no interaction of Naringenin with amino acids of the protein $1 \mathrm{BHG}$.

The screening of the three flavonols derivatives (Naringenin, Quercetin and 2-(3, 4-Dihydroxy Phenyl)7-Hydroxy-3-(2-Hydroxy Ethoxy) 4-H-Chromen-4one) compounds, were subjected for estimation of inhibitory 
Table 3: Representation of Absorbance and $\beta$-Glucuronidase Inhibition (\%) of Different Compounds at Different Concentrations after $\mathbf{6 0}$ Minute of Incubation

\begin{tabular}{|c|c|c|c|c|}
\hline Tested compounds & Conc. $(\mu \mathrm{g} / \mathrm{ml})$ & $\begin{array}{l}\text { Absorbance of the } \\
\text { sample after incubation }\end{array}$ & $\begin{array}{l}\text { (\%) of inhibition of } \beta- \\
\text { glucuronidase activity }= \\
{\left[\left(\text { Abs control }- \text { Abs }_{\text {test }}\right) /\right.} \\
(\text { Abs control })] \\
\times 100\end{array}$ & $\begin{array}{c}Y=m x+c \\
R^{2} \\
I C_{50}(\mu g / m l)\end{array}$ \\
\hline \multirow{4}{*}{ Quercetin } & 50 & 0.1 & $37.2 \pm 2.94$ & \multirow{4}{*}{$\begin{array}{c}Y=0.194 x \pm 27.39, \\
R^{2}=0.972, \\
I C_{50}=116.54\end{array}$} \\
\hline & 100 & 0.089 & $44.4 \pm 1.68$ & \\
\hline & 200 & 0.49 & $69.41 \pm 3.33$ & \\
\hline & 250 & 0.043 & $73.2 \pm 7.81$ & \\
\hline \multirow{2}{*}{ Naringenin } & 50 & 0.14 & $10.1 \pm 2.47$ & \multirow{2}{*}{$\begin{array}{c}Y=0.136 x \pm 7.55 \\
R^{2}=0.905 \\
I C_{50}=312.11\end{array}$} \\
\hline & 100 & 0.12 & $24.6 \pm 5.2$ & \\
\hline \multirow{5}{*}{$\begin{array}{l}\text { 2-(3, 4-Dihydroxy } \\
\text { Phenyl)-7-Hydroxy-3-(2- } \\
\text { Hydroxy Ethoxy) 4-H- } \\
\text { Chromen-4one }\end{array}$} & 50 & 0.065 & $59.3 \pm 9.24$ & \multirow{5}{*}{$\begin{array}{c}Y=0.223 x \pm 48.22 \\
R^{2}=0.948 \\
I C_{50}=7.98\end{array}$} \\
\hline & 100 & 0.052 & $67.2 \pm 8.66$ & \\
\hline & 150 & 0.025 & $84.3 \pm 10.24$ & \\
\hline & 200 & 0.003 & $98.4 \pm 3.21$ & \\
\hline & 250 & 0.001 & $99.6 \pm 6.24$ & \\
\hline
\end{tabular}

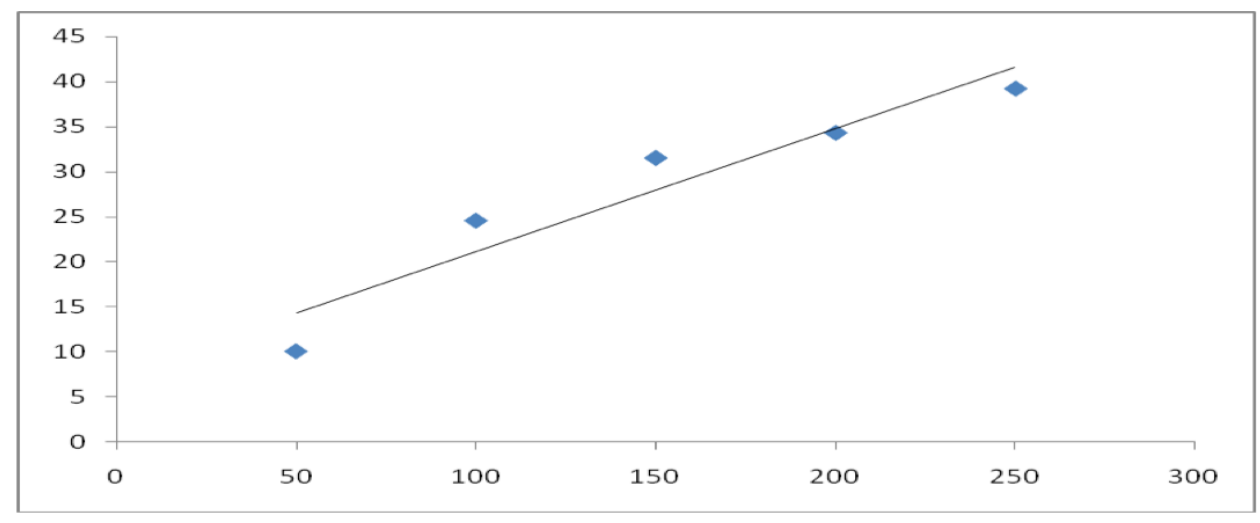

a

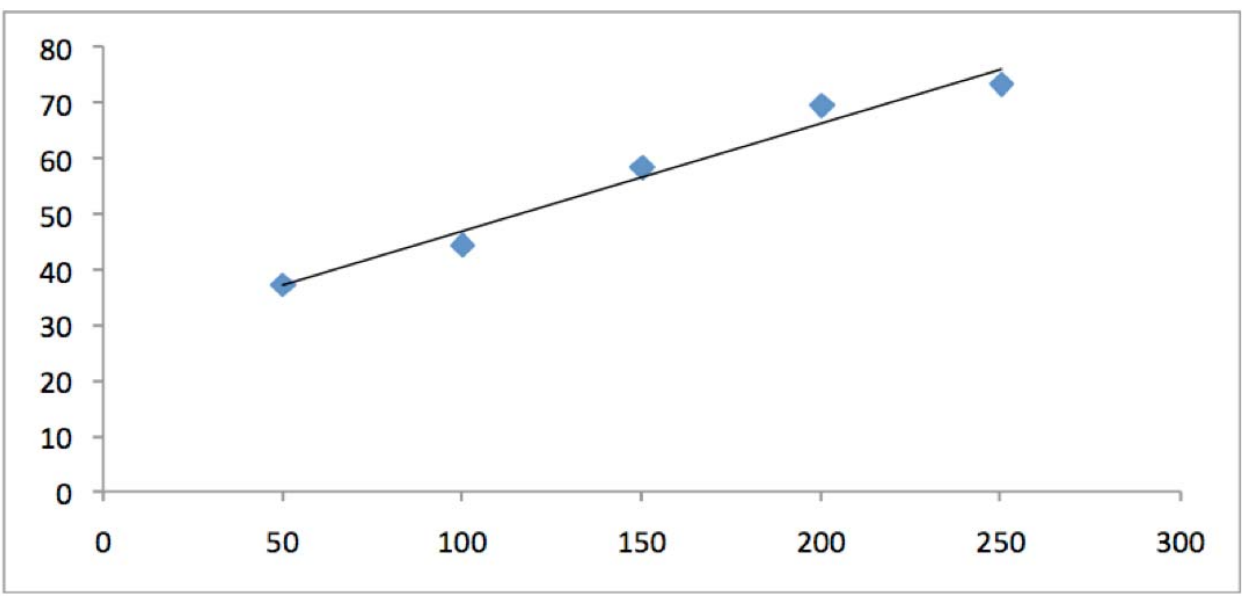




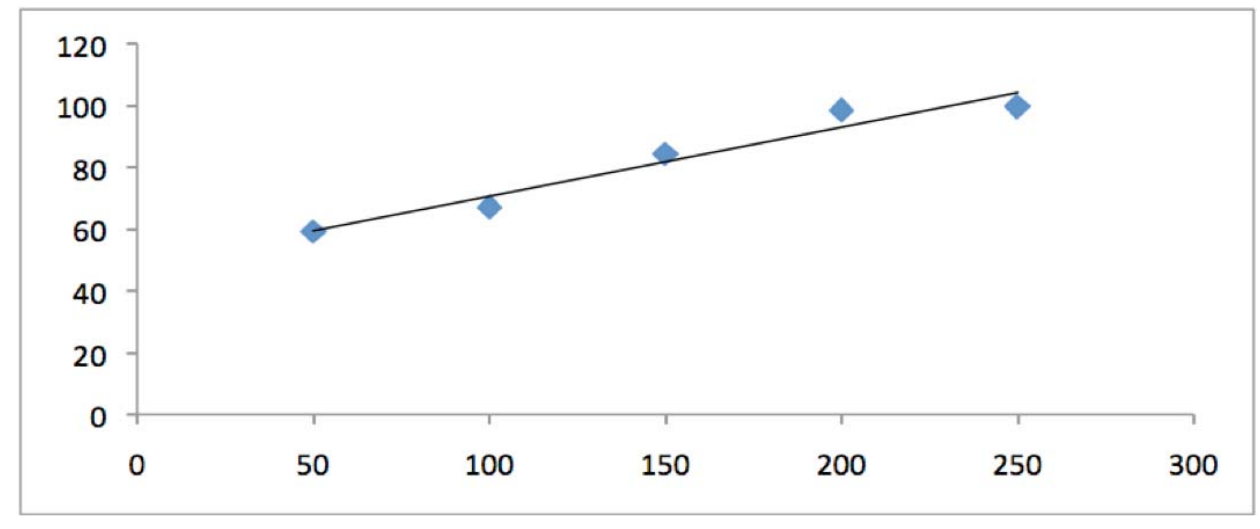

C

Figure 2: a: Graph representing \% of $\beta$-glucuronidase Inhibition Vs Concentration of Naringenin.

b: Graph representing \% of $\beta$-glucuronidase Inhibition Vs Concentration of Quercetin.

c: Graph representing \% of $\beta$-glucuronidase Inhibition Vs Concentration of 2-(3, 4-Dihydroxy Phenyl)-7-Hydroxy-3-(2-Hydroxy Ethoxy) 4-H-Chromen-4one.

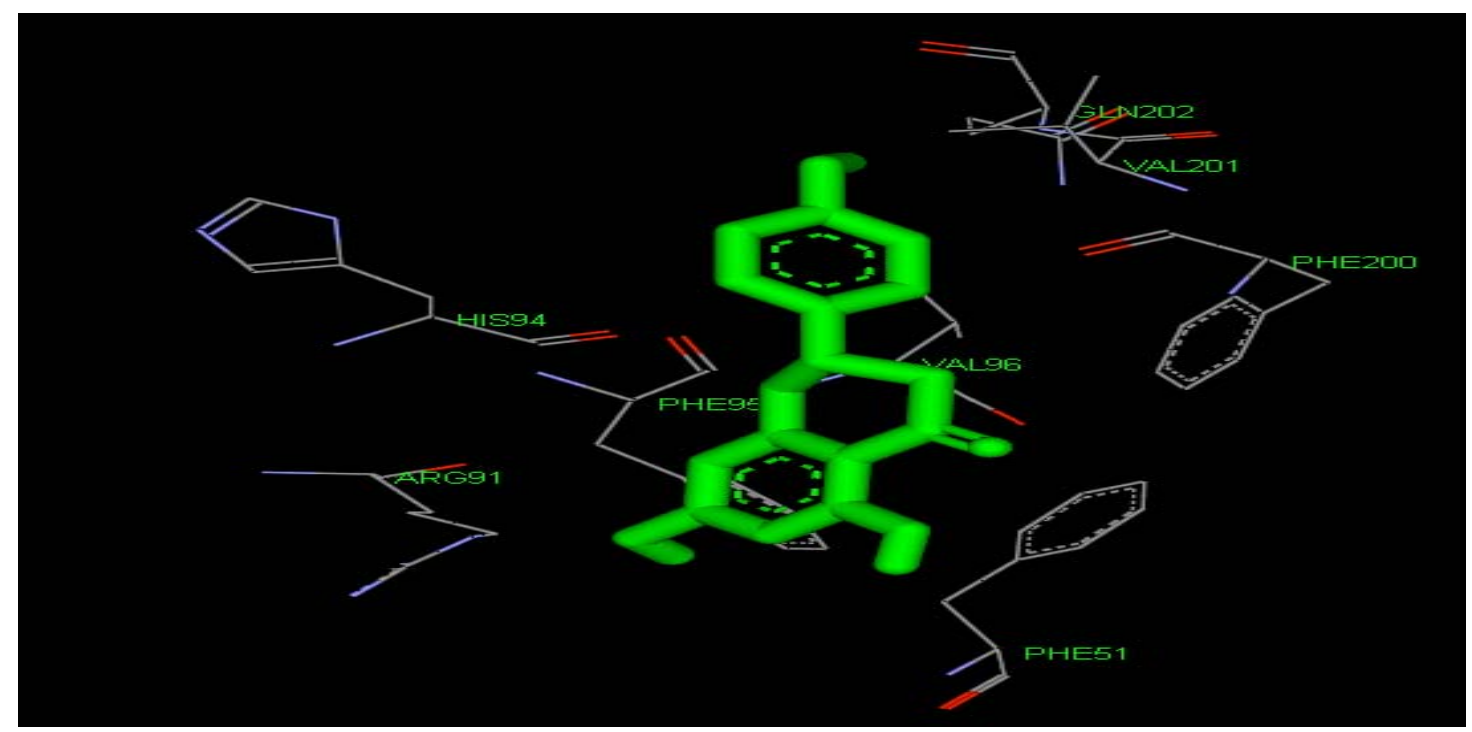

a

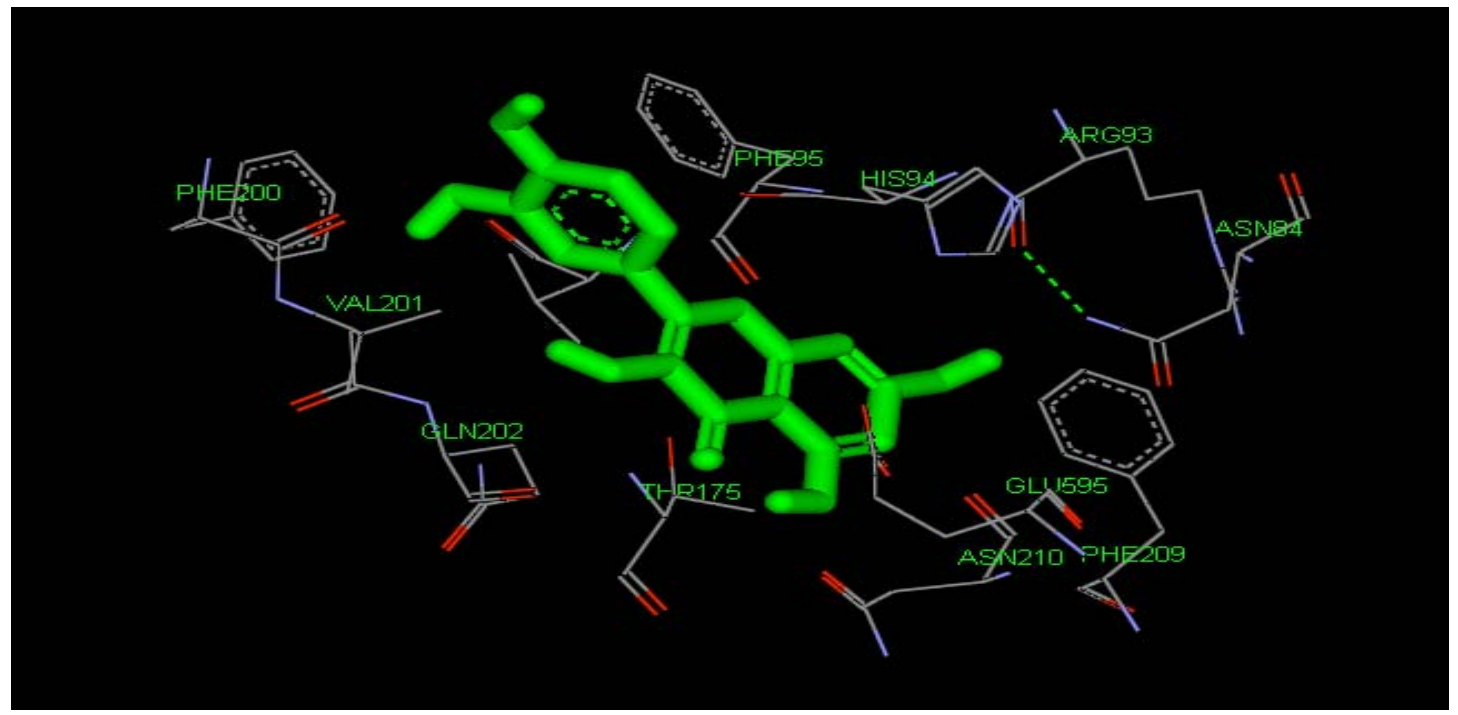


(Figure 3). Continued.

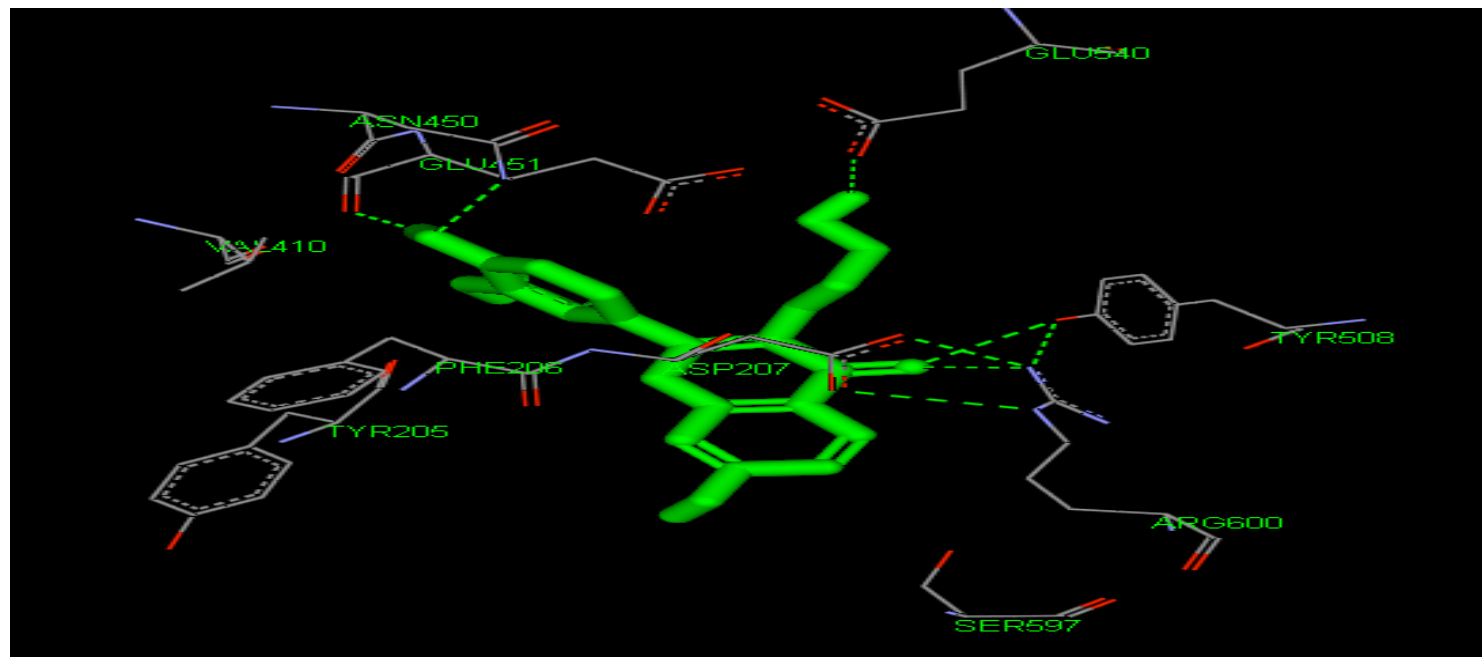

C

Figure 3: a: Predicted Bonded interaction (Green dashed lines) between Naringenin and $1 \mathrm{BHG}$.

b: Predicted Bonded interaction (Green dashed lines) between Quercetin and ASN81of 1BHG.

c: Predicted Bonded interaction (Green dashed lines) between ID 9818879 (2-(3, 4-Dihydroxy Phenyl)-7-Hydroxy-3-(2-Hydroxy Ethoxy) 4-H-Chromen-4one.) and GLU 451, GLU520, TYR508, ARG600, PHE206, ASN450 of 1 BHG.

potency of $\beta$-glucuronidase activity showed that the compound 2-(3, 4-Dihydroxy Phenyl)-7-Hydroxy-3-(2Hydroxy Ethoxy) 4-H-Chromen-4one exhibited excellent activity with an $\mathrm{IC}_{50}$ value $7.98 \mu \mathrm{g} / \mathrm{ml}$ which was 14 times more potent than the compound Quercetin $\left(\mathrm{IC}_{50}=116.54 \mu \mathrm{g} / \mathrm{ml}\right)$. Similarly, Naringenin exhibited poor activity with an $\mathrm{IC}_{50}$ value $312.11 \mu \mathrm{g} / \mathrm{ml}$ which was 2 times less potent than the compound Quercetin and 40 times less potent than the compound 2-(3, 4-Dihydroxy Phenyl)-7-Hydroxy-3-(2-Hydroxy Ethoxy) 4-H-Chromen-4one.

\section{DISCUSSION}

In silico approach provides an additional validation for the experimental findings by investigation through binding mode of flavonols derivatives. The previously finding report suggest the modelled substrate-bound structure of human $\beta$-D-glucuronidase showed that the glycoside bond of $p$-nitrophenyl $\beta$-glucuronide was linked towards the residue Glu451 (acid/base catalyst) and Glu540 (nucleophilic residue) [21]. This is further conformed that this two residue might be considered as the active site for $\beta$-D-glucuronidase. The result outcome of the binding orientation of 2-(3, 4-Dihydroxy Phenyl)-7-Hydroxy-3-(2-Hydroxy Ethoxy) 4-HChromen-4one linked with the active amino acid residue of the protein (Glu540 and Glu541) and the binding affinity ( -8.3 ) with existence of 8 numbers of hydrogen bonds which leads to find out the mechanism for its potential in-vitro inhibitory activity where as the lesser binding orientation of Quercetin and absence of binding orientation in Naringenin was the reason for lower potential inhibitory activity.

\section{CONFLICT OF INTEREST STATEMENT}

We declare that we have no conflict of interest.

\section{REFERENCE}

[1] Pattanaik S, Panda J, Sahu PK, Banerjee MB, Rout SS. Synthesis characterization and biological evaluation of bidentate ligands (Reduced Schiff's base) with metals of copper, nickel and Zinc complexes. Rasayan J of Chemistry 2006; 5: 136-141.

[2] Paul D. Structure-based virtual screening: an overview. DDT 2002; 720: 1047-1055.

[3] Rarey M, Kramer B, Lengauer T, Klebe G. A fast flexible docking method using an incremental construction algorithm. J Mol Biol 1996; 261: 470-489.

http://dx.doi.org/10.1006/jmbi.1996.0477

[4] Verschoyle RD, Steward WP, Gescher AJ. Putative cancer chemo preventive agents of dietary origin-how safe are they? Nature Cancer 2007; 59: 152-162.

[5] Rout SS, Pattanaik S, Si SC, Pal A, Sahoo RN, Mohanty P. Anti-Nociceptive activities of complexes of Naringin with $\mathrm{CO}$ (II) metal ions. Int J Pharm Pharm. Sci 2013; 5: 972-975.

[6] Rietjens IM, Boersma MG, van der Woude H, Jeurissen SM, Schutte ME, Alink GM. Flavonoids and alkenylbenzenes: mechanisms of mutagenic action and carcinogenic risk Mutat Res 2005; 574: 124-138. http://dx.doi.org/10.1016/j.mrfmmm.2005.01.028

[7] Pattanaik S, Si SC, Rout SS, Nayak SS. Evaluation of hepatoprotective and lipid peroxidation activity of the plant Crataeva magna Buch Ham (Capparidaceae). Der Pharmacia Lettre 2013; 5: 333-337.

[8] Stahl PD, Fishman WH. $\beta$-D-glucuronidase, In: Method of Enzymatic Analysis. (Ed. Bergmeyer HU), $3^{\text {rd }}$ ed., Weinheim, Verlag Chemie 1984; p. 246-256. 
[9] Pineda EP, Goldberg JA, Banks BM, Rutenburg AM. The significance of serum $\beta$-glucuronidase activity in patients with liver disease. Gastroenterology 1959; 36: 202-213.

[10] Mills GT, Smith EEB. The 3-glucuronidase activity of chemically induced rat hepatoma. Science 1951; 114: 690692.

http://dx.doi.org/10.1126/science.114.2974.690

[11] Levy GA, Kerr LMH, Campbell JC. $\beta$-Glucuronidase and cell proliferation. Biochem J 1948; 42: 462-468.

[12] Mills GT, Paul J, Smith EE. Studies in beta-glucuronidase. III. The influence of age, partial hepatectomy and other factors in the $\beta$-glucuronidase activity in rat liver. Biochem J 1953; 53: 245-253.

[13] Pattanaik S, Si SC, Pal A, Nayak SS. Evaluation of hepatoprotectve activity and isolation of 2-(3, 4-dihydroxy phenyl)-7-hydroxy-3-(2-hydroxy ethoxy) 4-H-chromen-4one from column fractions of leaves of the extract of Crataeva magna. Int. J Phytomedicine 2013; 5: 452-459.

[14] Berman HM, Westbrook J, Feng Z, Gilliland G, Bhat TN, Weissig $H$, Shindyalov IN, Bourne PE. The Protein Data Bank. Nucleic Acid Res 2000; 28: 235-242. http://dx.doi.org/10.1093/nar/28.1.235

[15] Jain S, Drendel WB, Chen JW, Mathews FS, Sly WS, Grub $\mathrm{JH}$. Structure of beta-glucuronidase reveals lysosomal targeting and active site motifs. Nat. Str. Biol 1996; 3: 375381.

http://dx.doi.org/10.1038/nsb0496-375
[16] Lipinski CA. Lead- and drug-like compounds. Drug Discov Today Technol 2004; 1: 337-341. http://dx.doi.org/10.1016/j.ddtec.2004.11.007

[17] Lipinski CA, Lombardo F, Doming BV, Feenay PJ. Experimental and computational approaches to estimate solubility and permeability in drug discovery and development settings. Adv Drug Deliv Rev 2001; 46: 3-26. http://dx.doi.org/10.1016/S0169-409X(00)00129-0

[18] Kumar DB, Kumar PV, Bhubaneswaran SP, Mitra A Advanced drug designing softwares and their application in medical research. Int J Pharm Pharm Sci 2010; 2: 16-18.

[19] Daisy P, Nivedha RP, Bakiya RH. In silico drug designing approach for biotin protein ligase of Mycobacterium tuberculosis. Asian J Pharm Clin Res 2013; 6: 103-107

[20] Sekikawa C, Kurihara H, Goto K, Takahashi K. Inhibition of beta-Glucuronidase by Extracts of Chondria crassicaulis. Bull Fish Sci Hokkaido Univ 2002; 53: 27-30.

[21] Khan KM, Rahim F, Halim SA, Taha M, Khana M, Perveen S, Zaheer-ul-Haq, Mesaik MA, Choudhary MI. Synthesis of novel inhibitors of beta-glucuronidase based on benzothiazole skeleton and study of their binding affinity by molecular docking. Bioorganic \& Medicinal Chemistry 2011; 19: 4286-4294. http://dx.doi.org/10.1016/j.bmc.2011.05.052 